\title{
New technique monitoring and transmission environmental data with mobile systems
}

\author{
Cannistraro G. ${ }^{1, *}$, M. Cannistraro M. ${ }^{2}$, Cao J. ${ }^{3}$, Ponterio L. ${ }^{1}$ \\ 1. Department of Engineering University of Messina, Messina, Italy \\ 2. Department of Architecture, University of Ferrara, Ferrara, Italy- \\ 3. Department of Thermal Science and Energy Engineering, \\ University of Science and Technology of China, Hefei 230027, China \\ gcannistraro@unime.it
}

ABSTRACT The deterioration of air quality in urban areas has become a problem to be reckoned with, the greater levels pollution, in addition to subject the inhabitants at risks substantial for the health, poses a risk potential of degradation of the historical-artisticarchitecture. The Department of Engineering of Messina together with the Department of Energetic and Environmental Researches (DREAM) of the University of Palermo, in cooperation with the Municipal Transport Company of Messina has development a project called "Project SET: Eco-efficient and Environmental Friendly Transport Systems". The project aims to define an integrated system of services to facilitate the deployment of ITS (Intelligent Transport System) solutions and of new techniques for the assessment of the urban microclimate and pollution conditions using original data acquisition equipments installed on moving vehicles. These instruments, equipped with various kinds of sensors, are able to measure the most important weather date and climate quantities and the most relevant pollution parameters and to save the position of the acquired data (latitude, longitude, altitude, speed) by means of a Global Positioning System (GPS). Data can be downloaded from a remote station through the GSM/GPRS mobile phone network. These equipments, continuously moving across the urban area, could integrate the data coming from existing fixed stations, and create a virtual network of hundreds of measuring points. In the field of the pollution control they can contribute to the characterization of causes, the localization of sources and to the application and check of control strategies with a relevant spin-off to town planning.In this paper the research activities carried out by the Departments of the two Universities of Messina and Palermo within the SET project and prototype of a standalone unit for detection and remote data acquisition are described.

RÉSUMÉ. La détérioration de la qualité de l'air dans les zones urbaines est devenue un problème avec lequel il faut compter. Les niveaux de pollution plus élevés, en plus de soumettre les habitants à des risques substantiels pour la santé, représentent un risque potentiel de dégradation de l'architecture historico-artistique. Le département d'ingénierie de Messine et le département de recherches énergétiques et environnementales (DREAM) de l'Université de Palerme, en coopération avec la société de transport municipal de Messine, ont développé un projet intitulé "Projet SET: Systèmes de transport éco-efficaces et 
respectueux de l'environnement." Le projet vise à définir un système intégré de services facilitant le déploiement de solutions ITS (Intelligent Transport System) et de nouvelles techniques d'évaluation du microclimat urbain et des conditions de pollution à l'aide d'équipements d'acquisition de données originaux installés sur des véhicules en mouvement. Ces instruments, équipés de différents types de capteurs, sont capables de mesurer les données météorologiques les plus importantes et les paramètres de pollution les plus pertinents, ainsi que de sauvegarder la position des données acquises (latitude, longitude, altitude, vitesse) par un Système de Positionnement Global (GPS). Les données peuvent être téléchargées par une station distante via le réseau de téléphonie mobile GSM / GPRS. Ces équipements, se déplaçant continuellement à travers la zone urbaine, pourraient intégrer les données provenant de stations fixes existantes et créer un réseau virtuel de centaines de points de mesure. Dans le domaine de la dépollution, ils peuvent contribuer à la caractérisation des causes, à la localisation des sources ainsi qu'à l'application et la vérification des stratégies de contrôle avec des sous-produits pertinentes pour la planification urbaine. Cet article décrit les activités de recherche menées par les départements des deux universités de Messine et de Palerme dans le cadre du projet SET et le prototype d'une unité autonome pour la détection et l'acquisition de données à distance sont décrites.

KEYWORDS: urban microclimate, urban pollution, mobile monitoring devices, remote data acquisition.

MOTS-CLÉS: microclimat urbain, pollution urbaine, dispositifs de surveillance mobiles, acquisition de données à distance.

DOI:10.3166/I2M.17.549-562 @ 2018 Lavoisier

\section{Introduction}

With the latest directives, the countries members of the International Treaty, they have imposed of the deadlines for the reduction of polluting emissions, to combat global warming, and have set the most stringent values for the permissible values.

The pollutant emissions, are mainly constituted by the products of combustion for heating of environments, for the generation of energy or by motor traffic.

These pollutants in addition to compromising the area, next to the emission sources, are transported for long distances, react chemically with the substances present in the atmosphere, resulting in the formation of secondary pollutants, such as acid rain and ozone production. One of the main problems for the improvement of urban air quality is that of reductions of the traffic emissions.

The environmental researches upon the main characteristic parameters of an urban atmosphere, both from a climatic point of view (temperature, relative humidity, solar irradiation, wind direction and wind speed), that from pollution viewpoint (chemicals, gases, dusts), are usually carried out by fixed stations, which are placed in some nodal points of the city grid.

It is worth noting that often the choice of the placement of these fixed stations does not follow the proper requirements for measure representativeness, but it often follows other factors such as spaciousness of the site, management comfort, safety and fast connection with hydraulic, electric, telephone and web systems. 
An acquisition data network of fixed stations does is not detected suitable, for the survey of climatic or polluting critical events (hot-spots) that may happen in urban areas (Weijers et al., 2004).

To control the possible risks caused by the presence of pollutants in urban, the municipalities have created of land monitoring networks, for the control the dangerous pollutants levels, that may produce harm to health of the inhabitants.

\section{Environmental monitoring literature}

The survey on the main characteristics of the urban climate, both from the meteorological point of view (temperature, relative humidity, irradiation, direction and speed of the wind) and pollution in the broader sense (chemical agents, gases, powders), is usually conducted through the installation of fixed measurement centers located in some points of the urban area.

Often, however, the positioning of the control units is done obeying criteria that are not exclusively those of the representativeness of the measures, but rather based on criteria of space, comfort of management, security and connection with the hydraulic, electrical, telephone or Internet networks.

A similar data acquisition network is not able to discover critical situations (hotspots) that can occur within the urban fabric (Weijers et al., 2004).

The average over a long period of observation from many stations can give an idea of the trend of the climatic characteristics of a large area, but the data are not referable to any particular point and to a particular moment. An extensive knowledge of the microclimatic conditions and pollution of a city area is of extreme interest for the definition of well-being indicators in the external environment, and for the identification of models of diffusion of traffic pollution and other anthropogenic activities to micro and mesoscale.

The installation of a large number of control units located throughout the urban territory, could allow to obtain detailed information of the territory, but this is not always feasible for obvious reasons of costs related both to the control units themselves, and to their management and maintenance.

A suitable alternative is to integrate the information provided by the fixed monitoring network, with a series of observations detected by moving vehicles, provided by simple and inexpensive control units, mounted on public means of the urban and/or extra-urban transport network. Studies carried out in recent years (Bitan, 1982; Seakins et al., 2002; Bukowiecki et al., 2002; Vogt et al., 2003) have shown that mobile laboratories have proved extremely useful for providing significant data sets.

The data recorded by the vehicles in continuous movement on the main road axes, can constitute a virtual network composed of a very high number of measuring stations. 
Pirjola et al. (2004) carried out a study in close collaboration with the Helsinki Polytechnic; a mobile laboratory was used to measure in real time the pollutants due to urban traffic with high spatial and temporal resolution.

Ojima (1990) in Tokyo, has using subway vehicles from one area of the city to another, to perform a campaign of temperature and humidity measures.

\section{Feasibility studies}

Feasibility studies on environmental monitoring by mobile means, in the cities of Palermo, Messina and Beijing were performed by Costanzo et al. (2006). The sensors installation, upon mobile transportation means, represents a new and clever solution.

In fact, only recently this kind of surveys became realizable, since mobile telephone systems based on GPRS/GSM mobile data services, have reduced significantly the prices.

For some years, the researchers of the Department of Energy of the University of Messina and Palermo, have experimented new techniques for analyzing and monitoring urban microclimatic conditions.

These monitoring techniques are based on the use of georeferenced data logged by acquisition systems placed upon moving means of transportation.

A measurement campaign was carried out in the city of Messina, by the Universities of Messina and Palermo, in collaboration with the Municipal Transport Company of Messina (A.T.M.), in order to evaluate the reliability of a stand-alone system, that provides georeferenced information in real time.

The units of acquisition data, have been mounted on the tramcars, that follow assigned lines, with the aim to test the accuracy of the GPS georeferencing system.

The tram system of Messina, are proved very reliable for the purposes of this research; in fact the route of the tramline runs almost entirely through not very high buildings, assuring a good signal level for the GSM transceiver and a good satellite covering for the GPS receiver (see Figure 1).

With this precious experimental knowledge, gained by scientific studies on Palermo and Messina, the Authors were able to create very reliable hardware units and software routines, for the acquisition and transmission of almost every kind of georeferenced data, through mobile means of transportation.

In fact, these devices may be equipped with many and diverse sensors, in order to record the most interesting climatic parameters and the most significant air pollutant agents.

Moreover these devices may be equipped with special communication software routines for saving the physical data and GPS data (latitude, longitude, altitude and velocity) by remote station by using the GSM/GPRS cellular network. 
The data collected by fixed monitoring stations, actually used, could be associated at the data collected by moving units, with the aim to create a virtual network constituted by hundreds of measuring points (Khan et al., 2013; Lillehoj et al., 2013; O’Driscoll et al., 2013; Nazelle et al., 2013; Lane et al., 2010; Aitkenhead, 2013; Novella, 2013; Aitkenhead et al., 2014; Kanio et al., 2010; Kaoutit et al., 2013), Cannistraro et al., 2013, Cannistraro et al., 2016, Cannistraro et al., 2018).

Georeferenced data may contribute to characterize, the causes and sources of pollution, for apply and to experiment planning of pollution control strategies by traffic (Seakins et al., 2002; Pirjola et al., 2004).

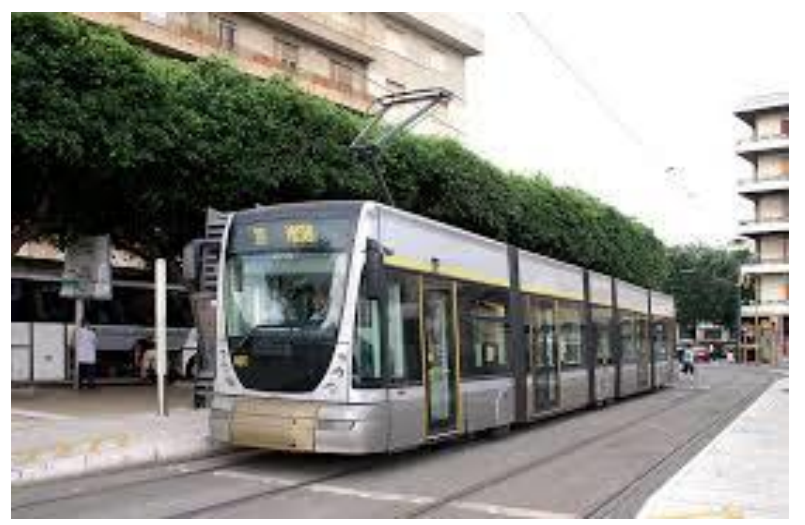

Figure 1. Tram of the municipal transport of Messina

\section{The set project}

The Municipal Transport Company of Messina, in collaboration with the Universities of Palermo, Messina, worked out a project named "Project SET-Eco efficient and Environmental Transport Systems Friendly", having the following aims:

a) the characterization of an integrated system of services, for an easy diffusion of solutions (ITS- Intelligent Transport System) in local public transport companies.

b) the study and the implementation of systems for:

- fleet management: passengers computation, dynamic allocation of cars on the routes, updating of schedules in real time;

- Security: monitoring and alarm generation;

- Innovative services: environmental monitoring real-time with road condition and traffic information.

\subsection{Research developments}

The research work of the Departments of Energy for the SET project, consisted 
of the implementation of a prototype of a standalone unit for the acquisition and transmission of georeferenced environmental parameters.

The research activity was developed in the following steps:

- First step: a comprehensive and thorough market research, has been carried out among the leading companies of measuring equipment and systems transceivers.

- And have been found, the most suitable sensors/transducers and the hardware and software platforms for measurement systems and remote data transmission;

- Second step: the problems of interfacing between a measuring device and a data acquisition hardware have been handled, and a firmware was developed.

The reliability of the firmware of data acquisition, the conversion in engineering units and the memorization of the converted data has also been tested.

The data acquisition standards unit, has been set up for:

- Acquire physical quantities with a proper precision level, and with a fixed or variable time step according to the position and speed of the moving instrumentation

- Recording position data, of each acquired information (time, latitude, longitude, height, speed) by a satellite-based global position system (GPS).

- Downloading the data in real time, from one or more fixed stations by connection to the mobile telephone network (GSM/GPRS).

- Storing of all data, into a non-volatile memory (EEPROM) until the data have been transferred to a remote Data-Base.

The collected data are constituted of:

- Temperature

- Relative Humidity

- Carbon Monoxide CO

- Ozone $\mathrm{O}_{3}$

- Particulate $\mathrm{PM}_{0.3}, \mathrm{PM}_{0.5}, \mathrm{PM}_{1}, \mathrm{PM}_{2}, \mathrm{PM}_{5}, \mathrm{PM}_{10}$

These two parameters thermo-hygrometric will be associated with other global parameters, such as direct and diffuse solar irradiation, wind speed and direction (easily obtainable from fixed stations), with the purpose to study, main bioclimatic indexes useful for the determination of the risk environmental thermal.

Obviously, there are numerous and various air quality parameters to take into account: the authors had to limit the number of sensors, for sake of simplicity and economy, and they have chosen the two most important (as suggested the World Health Organization (WHO- Environmental Health Criteria 213, Draft 2004).

In particularly, they have chosen the Carbon monoxide $(\mathrm{CO})$ and Ozone, $\left(\mathrm{O}_{3}\right)$ as pollutant parameters, and six sizes of the Particulate Matter, PTS.

The most important outdoor CO sources, are due at the engine exhausts, study on the Carbon Monoxide, could be particularly interesting, in particular on the traffic composition, on aging and maintenance of the cars. 


\subsection{Equipment description}

During the design of the measurement equipment, the authors tried to come to a possible compromise between the following different requirements:

- Strength and resistance to atmospheric agents.

- Easiness of installation, maintenance and calibration: good precision of its and component devices, to obtain useful and significant measurements.

- Easy interface with processing unit and internal data acquisition.

- Low price.

Therefore the used instrumentations show the following characteristics:

- OEM model (Original Equipment Manufacturer), only constituted of the measuring sensor and the electronic board for the signal conditioning, the analogical to digital conversion and the digital data transmission.

- Equipped with bi-directional interface for data control and transmission with the same protocol. In Particularly RS232 standard interface has been chosen, as the most used among OEM instrumentations.

- Power supply requirements not over 24 Volt, to utilize bus batteries.

Two unit, pre-prototypes of measurement have been tuned up, they were equipped with a GPS positioning system, a GSM (Figure 2).

A series of tests have been effectuated with the purpose of verify data transmission safety and continuity upon the investigated territory by mobile phone, with the purpose to verify the strength of GPS satellite signals in urban areas and in extra-urban areas (Khan et al., 2013; Kaoutit et al., 2013).

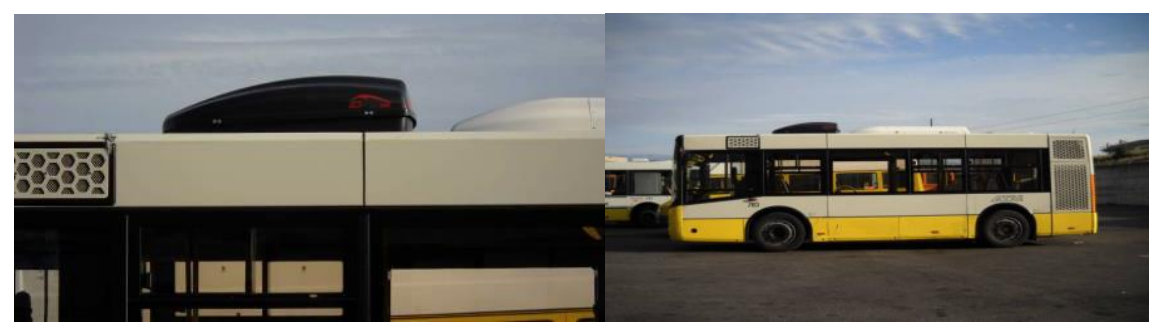

Figure 2. Bus 783 bus equipped with the prototype

A test unit has been installed upon a tramcar of the Municipal Transport Company of Messina (A.T.M.), named bus 783, while a second unit has been used for testing the hardware and software changes, with the purpose of optimization the units, in function field of data

Another aim of this first investigation was the implementation of a "time and distance" measurement strategy. 
The data were acquired, only if the vehicle has covered an assigned distance, from a measure point to another or only if a fixed time gap was elapsed between a measure and the next one.

This measurement strategy allows to avoid the storing of too many data in a same measure point, e.g. at bus stops, and it allows to spacing out the data when the vehicle is moving at different speeds.

Moreover, the opportunity of acquiring data in assigned points, close to fixed measuring stations, with the purpose to realize a data validation after the comparison.

\subsection{Measurement unit specifications}

The system acquires the following route data:

- Number of GPS satellites in sight

- Latitude

- Longitude

- Altitude

- Speed

- GMT date e time

And the following data from the sensor aboard:

- Temperature

- Relative Humidity

- Particulate (6 catg. $=0.3,0.5,1.0,2.0,5.0,10 \mu \mathrm{m})$

- Percentage of Carbon Monoxide in air

- Ozone ppm

Every datum, from each record is sent by GPRS connection to the WEB site of A.T.M. (Municipal Transport Company of Messina), that contains some PHP scripts, useful for saving it in MySQL Database.

For safety's sake, a copy of a whole day data, is saved in appropriate text files, on a USB pen-drive, positioned aboard of the equipment.

Using the Google Earth public software, the acquisition points may be highlighted as waypoints (WPT) upon the map or upon the satellite photo.

The main results of a pilot monitoring survey of air pollution and on climatic parameters in the urban area of the city of Messina is also shown (Kanjo, 2010).

As an example, the maps with waypoints recorded on 9th and 11st of May 2009 (Figure 3) and a georeferenced picture (Figure 5) of all the bus 783, route points during the week from the 6th of May to the 12th of May 2009, in the city of Messina, are shown.

In the picture of Figure 4, the points marked, are the ones in which the 
measurement equipment lost its GPRS contact, or the phone contact has been obtained only after several attempts.

These points, together with other measurements, from other moving vehicles, may be used for highlighting the probable "dead-zones" in the transmission data system.

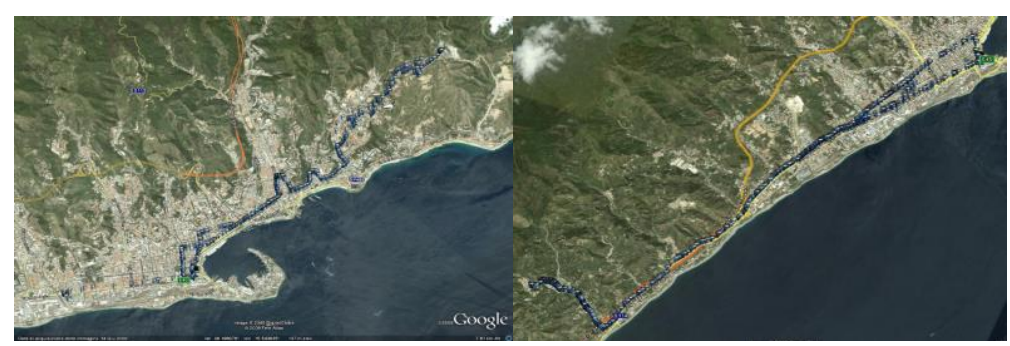

Figure 3. Maps with waypoints recorded 9 May 2009

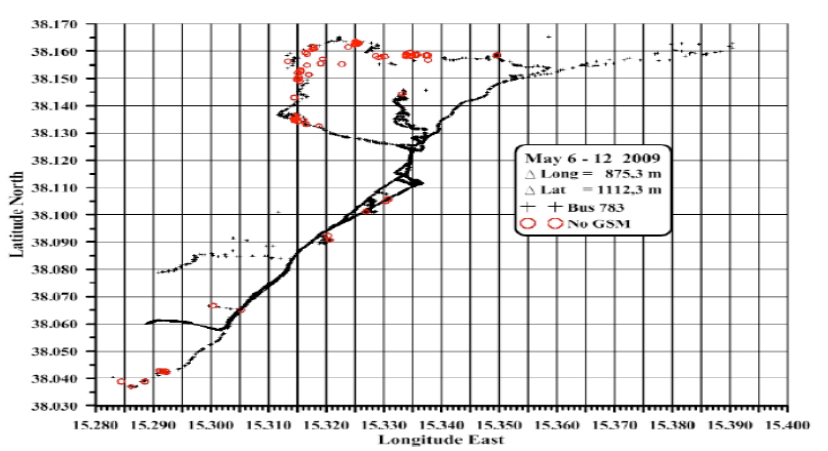

Figure 4. Georeferenced points of the Bus 783

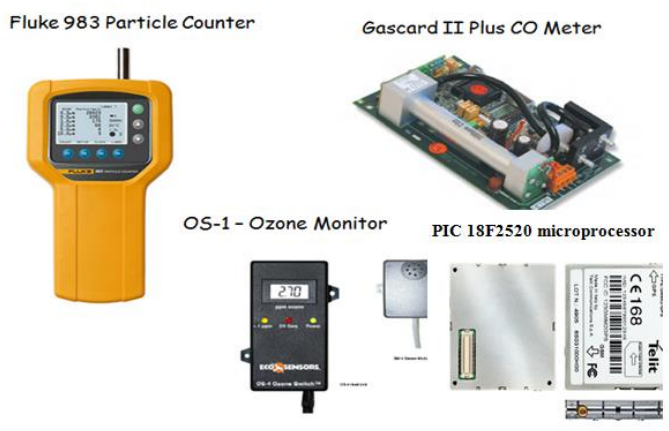

Figure 5. Prototype measurement devices 
After verifying the good working of the data transmission equipment and after setting up the software to connect with the Internet network, the authors realized a first complete prototype, with the assembling of the measurement devices (see Figure 6) at the platform of the operating system, with standard interfaces RS232.

By the use of this methodology an unlimited number of stations units, may connect to the Internet network and they may send data to the server, so researchers may obtain in a real-time position, the environmental parameters by all the moving units without call them one at a time (polling). In the Figure 6 are shown respectively: the real-time values of the detected pollutants.

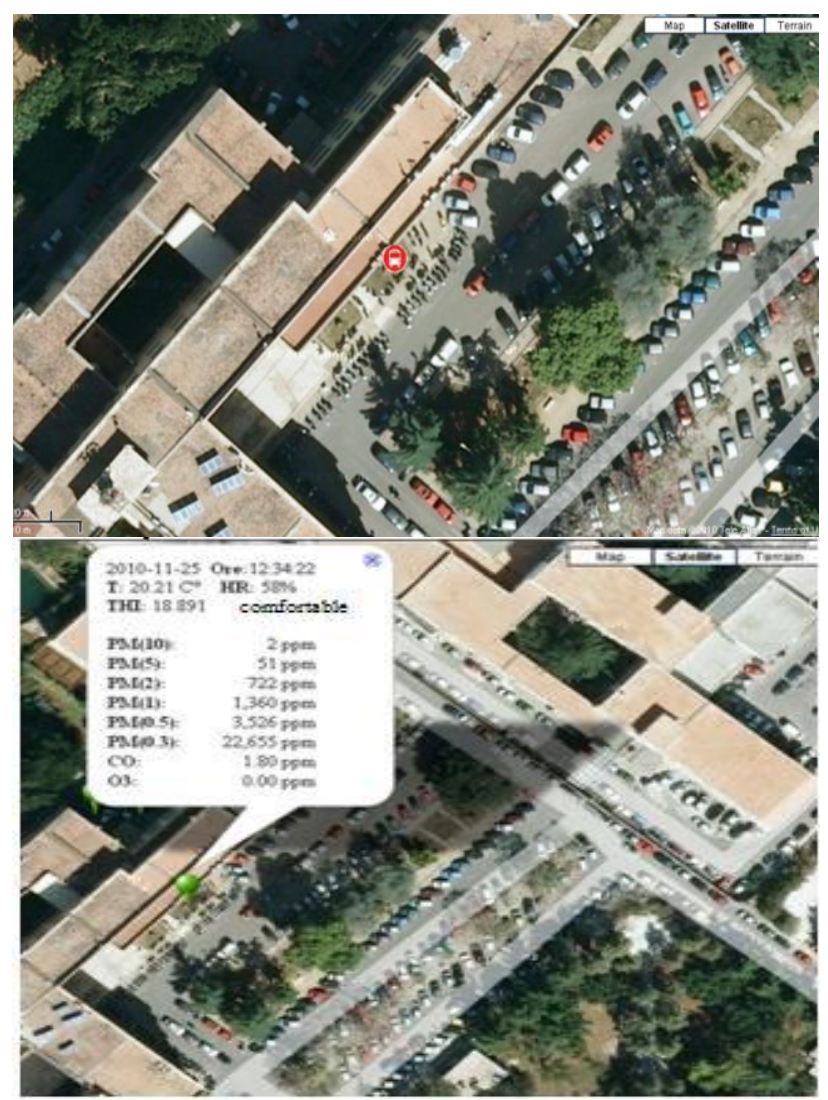

Figure 6. Real-time values detected pollutants

The Figure 7 and Figure 8, show respectively: the measures of ozone $\left(\mathrm{O}_{3}\right)$ and carbon monoxide $(\mathrm{CO})$, detected in waypoints. Available on the server, the data may be acquired in appropriately, for allowing a harmonization format coming from the different research group of the SET Project. 


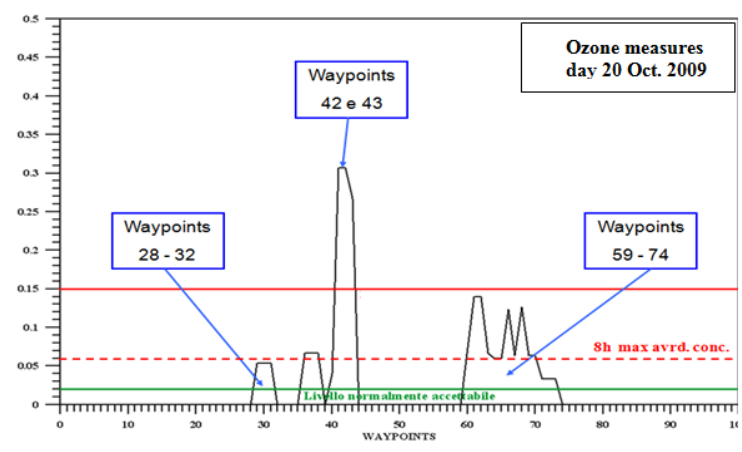

Figure 7. Measure of ozone, $\mathrm{O}_{3}$ detected in waypoints

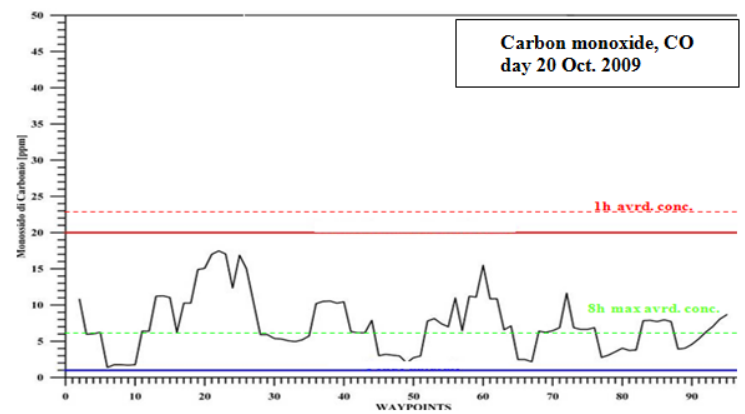

Figure 8. Carbon monoxide CO detected in waypoints

\section{Conclusions}

The research project developed of the two Departments of Messina and Palermo, within the SET Project, had as object the realization of a standalone unit for the detection, acquisition and broadcasting of georeferenced environmental data.

The installation of sensors aboard moving vehicles showed to be a new, smart, as well as cheap, choice that allowed a right integration of the systematic data collected by fixed monitoring stations, with the extensive data collected by the moving vehicles.

The advantages of a virtual monitoring network composed by moving means of transportation, may be summarized in the following points:

- For universities and research centre, a wide and exhaustive knowledge of urban microclimatic and pollution conditions, appears extremely interesting for the improvement in urban heat island investigations. In particular in the urban canyons, the energy transfer studies, the assessment of the comfort indexes outdoor, in 
pollution diffusion models, and in all complex issues energy saving at micro- and meso-scale.

- For the Public Transportation Companies, availability in real time of georeferenced data is absolutely necessary for fleet control, for information at users about wait times at the stops or about service breaks, for telecontrol of vehicles and mechanical working, and for the actions of measures precautionary, for the staff abuses or vandalism gestures.

- For municipalities concerned with the field of urban pollution control, this kind of monitoring network will allow:

- verification and determination of causes;

- characterization and localization of sources;

- drawing of pollutants diffusion maps;

- application and verification in real time of control strategies;

- drawing up of sustainable town-plans and development of an "energy conscious" town planning model.

At last, a monitoring network integrated by moving vehicles will be able to give an aid for all the activities of national safety public departments.

\section{References}

Aitkenhead M. J., Donnelly D., Coull M. C., Hastings E. (2014). Innovations in environmental monitoring using mobile phone technology - a review. International Journal of Interactive Mobile Technologies, Vol. 8, No. 2, pp. 42-50. http://dx.doi.org/10.3991/ijim.v8i2.3645

Aitkenhead M. J., Donnelly D., Coull M. C. (2013). Innovations in aquatic monitoring. CREW project number CD2013_04. http://crew.ac.uk/publications.

Bitan A. (1982). The Jordan Valley Project - a case study in climate and regional planning. Energy and Buildings, Vol. 4, No. 1, pp. 1-9. https://doi.org/10.1016/03787788(82)90013-5

Bukowiecki N., Dommen J., Prevot A. S. H., Richter R., Weingartmen E., Valtensperger U. (2002). A mobile pollutant measurement laboratory-measuring as phase and aerosol ambient concentrations with high spatial and temporal resolution. Atmospheric Environment, Vol. 36, No. 36-37, pp. 5569-5579. https://doi.org/10.1016/S13522310(02)00694-5

Cannistraro M., Cannistraro G., Piccolo A., Restivo R. (2013). Potential and limits of oxidative photocatalyses and possible applications in the field of cultural heritage. Advanced Materials Research, Vol. 787, pp. 111-117. http://dx.doi.org/10.4028/www.scientific.net/AMR.787.111

Cannistraro M., Cao J. Y., Ponterio L. (2018). Experimental study of air pollution in the urban centre of the city of Messina. Modelling, Measurement and Control C, Vol. 79, No. 3, pp. 133-139. https://doi.org/10.18280/mmc_c.790311 
Cannistraro G., Cannistraro A., Cannistraro M., Galvagno A., Trovato G. (2016). Analysis of the air pollutions in the urban center of four sicilian cities. International Journal Heat \& Technology, Vol. 34, pp. S219-225. https://doi.org/10.18280/ijht.34S205

Cannistraro M., Restivo R. (2018). Monitoring of indoor microclimatic conditions of an eighteenth-century church, with wireless sensors. Advances in Modelling and Analysis B, Vol. 61, No. 1, pp. 28-36. https://doi.org/10.18280/ama_b.610106

Trancossi M., Kay J., Cannistraro M. (2018). Peltier cells based acclimatization system for a container passive building. Italian Journal of Engineering Science: Tecnica Italiana, Vol. 61+1, No. 2, pp. 90-96. https://doi.org/10.18280/IJES.620106

Costanzo S., Cusumano A., Giaconia C., Mazzacane S. (2006). The study of the urban microclimate by means of public transport systems. Proceedings of the 5th WSEAS Intern. Conference on Environ. Ecosystems and Development, Venice, pp. 106-111.

Kanjo E. (2010). NoiseSPY: A real-time mobile phone platform for urban noise monitoring and mapping. Mobile Networks \& Applications, Vol. 15, No. 4, pp. 562-574. http://dx.doi.org/10.1007/ s11036-009-0217-y

Kaoutit H. E., Estevez P., Garcia F. C., Serna F., Garcia J. M. (2013). Sub-ppm quantification of $\mathrm{Hg}(\mathrm{II})$ in aqueous media using both the naked eye and digital information from pictures of a colorimetric sensory polymer membrane taken with the digital camera of a conventional mobile phone. Analytical Methods, Vol. 5, No. 1, pp. 54-58. http://dx.doi.org/10.1039/c2ay26307f

Khan W. Z., Xiang Y., Aalsalem M. Y., Arshad Q. (2013). Mobile phone sensing systems: A survey. IEEE Communications Surveys and Tutorials, Vol. 15, No. 1, pp. 402-427. http://dx.doi.org/10.1109/SURV.2012.031412.00077

Lane N. D., Miluzzo E., Lu H., Peebles D., Choudhury T., Campbell A. T. (2010). A survey of mobile phone sensing. IEEE Communications Magazine, Vol. 48, No. 9, pp. 140-150. http://dx.doi.org/10.1109/ MCOM.2010.5560598

Lillehoj P. B., Huang M. C., Truong N., Ho C. M. (2013). Rapid electrochemical detection on a mobile phone. Lab on a Chip, Vol. 13, No. 15, pp. 2950-2955. http://dx.doi.org/10.1039/c31c50306b

Nazelle A. D., Seto E., Donaire-Gonzalez D., Mendez M., Matamala J., Nieuwenhuijsen M. J., Jerrett M. (2013). Improving estimates of air pollution exposure through ubiquitous sensing technologies. Environmental Pollution, Vol. 176, pp. 92-99, http://dx.doi.org/10.1016/ j.envpol.2012.12.032

Novella S. (2013). Will your smartphone become a tricorder? Science based Medicine. http://www.sciencebasedmedicine.org/will-yoursmartphone-become-a-tricorder/), accessed on 5th Oct, 2013.

O'Driscoll S., MacCraith B. D., Burke C. S. (2013). A novel camera phone-based platform for quantitative fluorescence sensing. Analytical Methods, Vol. 5, No. 8, pp. 1904-1908. http://dx.doi.org/10.1039/c3ay40116b

Ojima T. (1990). Changing tokyo metropolitan area and its heat island model. Energy and Building, Vol. 15, No. 1-2, pp. 191-203. https://doi.org/10.1016/0378-7788(90)90131-2

Pirjola L., Parviainen H., Hussein T., Valli A., Hameri K., Aaalto P., Virtanen A., Keskinen J., Pakkanen T. A., Makelä T., Hillamo R. E. (2004). "Sniffer"- a novel tool for chasing 
562 I2M. Volume $17-n^{\circ} 4 / 2018$

vehicles and measuring traffic pollutants. Atmospheric Environment, Vol. 38, No. 22, pp 3625-3635. https://doi.org/10.1016/j.atmosenv.2004.03.047

Seakins P. W., Lansley D. L., Hodgson A., Huntley N., Pope F. (2002). New directions: Mobile laboratory reveals new issues in urban air quality. Atmospheric Environmental, Vol. 36, No. 7, pp. 1247-1248. https://doi.org/10.1016/S1352-2310(01)00584-2

Vogt R., Kirchner U., Scheer V., Hens K. P., Trimborn A., Spengler B. (2003). Identification of diesel exhaust particles at an Autobahn, urban and rural location using single-particle mass spectrometry. Journal of Aerosol Science, Vol. 34, No. 3, pp. 319-337. https://doi.org/10.1016/ S0021-8502(02)00179-9

Weijers E. P., Khlystov A. Y., Kos G. P. A., Erisman J. W. (2004). Variability of particulate matter concentrations along roads and motorways determined by a moving measurement unit. Atmospheric Environment, Vol. 38, No. 19, pp. 2993-3002. https://doi.org/10.1016/j.atmosenv.2004.02.045 